\title{
Editorial
}

\section{ASSURING THE QUALITY OF DRUGS USED FOR THE TREATMENT AND CONTROL OF LEPROSY}

Improvements in case-finding can make a significant contribution to reducing the prevalence and transmission of leprosy and the efficiency with which diagnosed patients are treated with the multidrug regimens recommended by the World Health Organization (WHO). ${ }^{1-7}$ In 1988 it was estimated that only about 5 million of the 10-12 million leprosy cases in the world had been diagnosed and registered for treatment. ${ }^{8}$ By 1990 , about 3 million patients had been placed on multidrug treatment. ${ }^{5}$ Currently, largely as a result of the continuing implementation of such treatment, the number of estimated cases has fallen to about 5.5 million. ${ }^{9}$ However, over 2 million of these estimated cases are as yet undiagnosed.

In tuberculosis, there is compelling evidence that the effective treatment of infectious, highly bacilliferous smear-positive patients is a more efficient method of controlling transmission than mass vaccination. ${ }^{10-13}$ It is likely that this is also true for leprosy. ${ }^{11,12}$ Chemotherapy diminishes the risk of infection by reducing the period during which patients are infectious, and so prevents some infections that would otherwise have occurred. Vaccination, by preventing cases of active disease following infection, eliminates the risk of further infections arising from the prevented cases. However, there are two important differences in the way in which chemotherapy and vaccination reduce the risk of disease transmission, and both favour chemotherapy as being more effective.

First, there is rapidity. Thus Shepard et al. ${ }^{14,15}$ showed that giving a single dose of 600 mg rifampicin to previously untreated lepromatous patients killed over $99 \%$ of the viable leprosy bacilli in their skin lesions within a week. An abrupt reduction in the infectiousness of lepromatous patients can therefore be expected as soon as they are started on WHO multidrug treatment. By contrast, future infectious cases prevented by vaccination of individuals at risk of infection would otherwise have arisen over many years since incubation periods for lepromatous leprosy are known to extend to at least 17 years. ${ }^{16}$

Secondly, there is practicality; the question of the relative feasabilities of delivering effective chemotherapy or vaccination to communities at risk. Thus it can be envisaged that the diagnosis and effective treatment of a high proportion of all active cases of multibacillary leprosy arising in a community each year can be achieved, especially when 
the availability of free or readily affordable effective multidrug treatment is well known. ${ }^{7}$ By contrast, large vaccination coverages are required to significantly reduce the transmission of leprosy or tuberculosis, because of their relatively slow transmission rates in even highly endemic situations, their long incubation periods, and the rarity of the most infectious (highly bacilliferous) forms of the diseases among children. ${ }^{10,17,18}$ Thus it has been calculated that giving a highly potent vaccine neonatally to all children in a highly endemic situation would reduce the transmission of tuberculosis by less than $2 \%$ per annum over a 15 -year period. ${ }^{10}$ In accord with such a prediction, similar declines in the morbidity and mortality of tuberculosis occurred over a 40 -year period in Scandinavia, where widespread BCG vaccination was employed, and in the Netherlands, where it was not. ${ }^{10}$ Furthermore, the introduction of effective chemotherapy resulted in markedly increased rates of decline of disease transmission. ${ }^{11}$

Although multibacillary patients form only a small fraction of all leprosy patients, their identification and effective treatment is a major objective of leprosy control efforts; first because lepromatous patients are the major source of transmission of the disease, and secondly, since their huge bacterial populations have the potential for allowing the selection of rifampicin- and high-level dapsone-resistant strains of Mycobacterium leprae ${ }^{19-23}$ that could eventually undermine the efficacy of available treatment.

\section{Effectiveness of the multidrug treatment recommended by the WHO}

The treatment recommended by the WHO for multibacillary patients is a combination of monthly supervised doses of rifampicin and clofazimine, and daily self-administered clofazimine plus dapsone given for at least 2 years, and if possible to smear negativity. When the recommendation was first published in $1982,{ }^{24}$ there was convincing evidence to suggest that if the drug regimen is delivered and ingested as recommended, it should prevent failures caused by the emergence of drug-resistant $M$. leprae and be effective irrespective of the patients' past treatment histories. It was also believed that any relapses that might occur af ter stopping treatment would be with fully drug-sensitive organisms so that patients would respond to further treatment with the same regimen, as is the case in pulmonary tuberculosis. ${ }^{25}$ It was also anticipated that because of the extremely marked bactericidal activity of rifampicin, such treatment should be capable of affecting a lasting cure in the great majority of patients, something that had never been achieved previously with dapsone monotherapy. It was therefore hoped that relapse rates after terminating treatment would be less than $1 \%$ per annum. ${ }^{19}$

These expectations have been more than fulfilled. Over 3 million patients have been treated with the recommended multidrug regimens whose acceptability has been highly satisfying. The pigmentation caused by clofazimine has not been a major obstacle to the treatment of light-skinned patients. There has also been a high level of patient satisfaction with their clinical response to the treatment and a significant reduction in the frequency and severity of ENL reactions, probably resulting from the inclusion of clofazimine in the regimen for multibacillary patients. ${ }^{26}$

Among more than 2000 patients whose treatment has been terminated for at least 6 years after achieving smear negativity in the 2 THELEP-supported Field Trials carried out in Karigiri and Polambakham in South India, not a single relapse has occurred. ${ }^{15.27,28}$ 
This indicates that persisting drug-sensitive bacilli, the so-called 'persisters' which appear unsusceptable to killing by rifampicin, dapsone and/or clofazimine, ${ }^{29}$ do not pose a significant threat of relapse following treatment termination. Apparent relapse rates among paucibacillary patients treated with 6 months daily dapsone and monthly rifampicin according to the WHO Study Group recommendations ${ }^{24}$ have also been very satisfactory. 5.30

\section{Operational considerations-improving treatment allocation and delivery and shortening the length of treatment}

It has become increasingly clear that because of the unsatisfactory way in which skin smears are often taken and stained, it would be both simpler and much less hazardous to initially classify multibacillary and paucibacillary patients on clinical grounds. ${ }^{31,32}$ Similarly it would be much simpler to give all multibacillary patients a total of 264-weekly treatments within a period of 3 years than to base treatment termination on achieving apparent smear negativity. ${ }^{31,33}$ The results of a study carried out in China strongly support such recommendations since termination of multidrug treatment after 2 years was followed by a steady continuing decrease in the bacterial indices. ${ }^{34}$ Excellent results have also been obtained with such fixed duration treatment in the THELEP-supported trials in South India and other parts of the world. ${ }^{35}$

Another important development has been the mass manufacture of blister-calendar packs for dispensing monthly allocations of dapsone, rifampicin and clofazimine. ${ }^{36-39}$ These are often made of robust triple laminated pvc polymer with aluminium foil backing so that they have very low moisture diffusion rates. They therefore protect the drugs from humidity, physical damage and dirt. They also discourage pilfering (particularly of rifampicin) since it is more difficult to remove large numbers of capsules and it is more noticeable than if they were taken from a large stock in bottles or tins. It is believed calendar packs may also encourage patient compliance, and dispensing drugs in this way makes it possible to check at a glance how many tablets have been removed at any time.

\section{Future chemotherapeutic developments}

It is evident that the potent antileprosy activity of the fluoroquinolones ${ }^{3}$ will enable highly effective multidrug regimens of much shorter duration to be designed for the treatment of multibacillary patients that will be considerably less vulnerable to the effects of poor patient compliance than standard multidrug therapy. ${ }^{23}$ Thus a recent controlled clinical trial showed that some $99.99 \%$ of the viable leprosy bacilli present in the skin lesions of previously untreated lepromatous patients were killed by just under 1 month's daily treatment with $400 \mathrm{mg}$ ofloxacin. ${ }^{40}$ Furthermore, the excellent bioavailability of orally administered ofloxacin has already been demonstrated by two studies in which serum levels and urinary excretion were compared after giving oral and intravenous doses of the drug. ${ }^{41,42}$ It therefore seems highly likely that 1 month's daily treatment with rifampicin plus ofloxacin could be at least as effective as 2 years standard multidrug treatment. A large multicentred trial to explore this possibility has recently been initiated. ${ }^{43,44}$ However, since it is based on relapse rates following treatment termination, it will probably be at 
least 4 years before the first significant results become available. Such a regimen would simplify treatment still further since it could be used for all patients and so obviate the need to classify patients on either bacteriological or clinical grounds prior to starting chemotherapy. In the meantime, standard multidrug therapy based on the use of dapsone, rifampicin and clofazimine will remain the sheet anchor of leprosy treatment.

\section{Quality control of antileprosy drugs: magnitude of potential bioavailability problems, their importance for the treatment and control of leprosy, and the assessment of their bioavailability}

For details of officially recommended methods for establishing the identity and drug contents of dapsone, rifampicin and clofazimine formulations, appropriate pharmacopoeias should be consulted. ${ }^{45,46}$ Informative monographs concerning their physicochemical properties, determination and pharmacology are also available. ${ }^{47-49}$ The key issue considered in this Editorial is how to ensure that tablets or capsules of dapsone, rifampicin or clofazimine containing the correct amounts of pure drug have been formulated in such a way as to secure optimal oral absorption.

\section{DAPSONE}

Despite the millions of patients that have been treated with dapsone since it was introduced in the early 1950s, there appears to be no evidence of any problems concerning its absorption. Recently the completeness of the absorption of orally administered dapsone has been formally confirmed in a cross-over study in which healthy volunteers were given both oral and intravenous doses of the drug. Identical dapsone serum concentration curves ('Areas under the curve-AUCs') were obtained. ${ }^{50}$

Daily treatment with $100 \mathrm{mg}$ dapsone leads to serum and tissue concentrations that are over 500 times its minimal inhibitory concentration against $M$. leprae. ${ }^{51-53}$ As a consequence even substantial reductions in dapsone bioavailability should be expected to have only the most minimal influence on the potency of multidrug treatment, since dapsone's ability to inhibit and kill dapsone-sensitive rifampicin-resistant mutants of $M$. leprae would be virtually unimpaired. ${ }^{19}$

The occasion might of course arise when it is necessary to confirm that a given batch of tablets did indeed contain the requisite amount of dapsone. This could readily be done by crushing the tablets and extracting the dapsone with an appropriate solvent such as acetone, ethyl acetate or methanol. ${ }^{48}$ The identity of the dapsone and the drug content of the tablets could then be established using either officially recommended ultraviolet or ampometric titration methods ${ }^{45}$ or alternative colorimetric, ${ }^{54}$ thin-layer chromatographic (TLC), ${ }^{55}$ fluorometric, ${ }^{56}$ or high-pressure liquid chromatographic (HPLC) procedures. ${ }^{57}$ TLC and HPLC methods have also been described for the identification and quantitation of impurities in dapsone preparations. ${ }^{58}$

\section{RIFAMPICIN}

The study undertaken by Levy et al. ${ }^{59}$ provides clearcut evidence concerning the marked influence of rifampicin dosage on its bactericidal activity against $M$. leprae. It compared 
the ability of single doses of $600 \mathrm{mg}$ rifampicin, with that of a series of consecutive daily $300 \mathrm{mg}$ doses of the drug, to render inocula from skin biopsies of previously untreated lepromatous patients noninfectious for mice. Leprosy bacilli from 11 of the 12 patients treated with a single $600 \mathrm{mg}$ dose of rifampicin lost their infectivity, indicating reductions in numbers of viable organisms of about $99 \%$. By contrast bacilli from 5 of 17 patients treated with either 3-5 or 7-9 daily doses of $300 \mathrm{mg}$ rifampicin retained their infectivity for mice. These results indicate that the bactericidal activity of a single $300-\mathrm{mg}$ rifampicin dose must be considerably inferior to that displayed by a standard $600-\mathrm{mg}$ dose, and provide convincing evidence that the efficacy of the WHO-recommended multidrug treatment would be greatly impaired if rifampicin formulations with substantially reduced bioavailability were used.

The absolute bioavailability of rifampicin was demonstrated in 2 fasting subjects by giving simultaneous 300 -mg doses of ${ }^{14} \mathrm{C}$-labelled rifampicin orally and ${ }^{3} \mathrm{H}$-labelled drug intravenously and measuring the areas under the serum concentration curves and cumulative urinary excretion of the 2 labels (Riess et al., cited in references 60 and 61). Absorption was, however, significantly impaired if rifampicin was ingested with or shortly after a meal (Riess, cited in references 60, 61 and 62).

The major route of elimination of rifampicin is by biliary excretion of the unchanged drug and its desacetyl metabolite. ${ }^{60}$ Rifampicin's serum half-life and the proportion of the dose excreted unchanged in the urine increases steadily as individual dose sizes are increased from 300 to $900 \mathrm{mg}$, probably as a result of the biliary excretion route becoming saturated. ${ }^{60}$ Daily rifampicin treatment for periods of a week or more results in the induction of a hepatic enzyme which deacetylates the drug. Since deacetylrifampicin is rapidly eliminated in the bile and not reabsorbed, ${ }^{63}$ such induction results in significantly reduced rifampicin half-lives.

Rifampicin's physicochemical properties and analytical methods for its determination have been reviewed. ${ }^{49,57,64}$ Rifampicin capsules or tablets should be kept in tightly closed containers, protected from heat, light and moisture. They have a shelf-life of 4 years. ${ }^{2}$

In the studies reported by Buniva et al. from Lepetit in Milan, ${ }^{65}$ serum rifampicin profiles are shown for 3 rifampicin formulations with impaired bioavailability that had been marketed by unlicenced manufacturers. A comparison of their peak rifampicin serum concentrations with those of Lepetit's own control formulations suggested that 2 had bioavailabilities of about $60 \%$, while that of the $3 \mathrm{rd}$ was only about $25 \%$. If the first 2 formulations had been used with dapsone and clofazimine for treating multibacillary leprosy patients, it would be anticipated that they would have resulted in suboptimal bactericidal activity, although they should still have killed $M$. leprae faster than a combination of dapsone and clofazimine. However, if the $3 \mathrm{rd}$ formulation had been used, all benefit of using rifampicin would probably have been lost. In many treatment settings the chances of noticing a slower than normal initial response to antileprosy chemotherapy would be very slight. It is also probable that the most important consequences of treatment with substandard rifampicin would be a higher risk of relapse af ter treatment termination.

At the end of their paper, Buniva et $a l .{ }^{65}$ described an extreme example of an unsatisfactory rifampicin capsule formulation that had been marketed by a non-licenced manufacturer, which had been brought to their attention because of its failure when used in the treatment of some leprosy patients. The capsules not only contained less than their stated amounts of rifampicin, they also had a 'high level of impurity' and an excipient 
(probably bentonite) which had previously been shown to impair rifampicin absorption. ${ }^{66}$ Unfortunately the paper did not reveal how long this rifampicin formulation had been used to treat the 7 patients concerned, the clinical or bacteriological evidence for its lack of efficacy, or whether it had been given with other antileprosy drugs. Similarly no information was provided concerning how extensively this particular rifampicin formulation had been marketed, whether its manufacturers were informed about its probable poor bioavailability, and if they were, whether it was then promptly withdrawn.

Buniva et $a l .{ }^{65}$ also presented evidence of the poor bioavailability of several 'experimental' rifampicin formulations with either non-standard particle sizes, altered excipients or manufacturing processes. It appears that rifampicin's crystalline structure can also critically influence its bioavailability ${ }^{67}$ and that while dissolution testing can provide a guide as to likely bioavailability, sometimes formulations with good dissolution properties are found to be poorly absorbed and vice versa. ${ }^{68}$

A recent report by Acocella from Lepetit ${ }^{69}$ described bioavailability studies on a series of single and combined rifampicin formulations. All the formulations containing rifampicin alone were shown to be satisfactory. However, 1 of 3 formulations containing rifampicin plus isoniazid was found to be unsatisfactory as were all 4 formulations containing rifampicin, isoniazid and pyrazinamide. Thus it appears that the difficulties of ensuring rifampicin's bioavailability are greatly increased when it is given in combined formulations with other drugs.

The implications of these findings for the treatment of tuberculosis with combined formulations of rifampicin, isoniazid and pyrazinamide of unproven bioavailability are serious ${ }^{70-73}$ since even small reductions in rifampicin dosage (f rom 600 to $450 \mathrm{mg}$ daily) are known to result in considerably slower sputum conversion rates. ${ }^{74}$ It should, however, be mentioned that satisfactory fully bioavailable combined formulations of rifampicin, isoniazid and pyrazinamide have been manufactured for either daily or intermittent tuberculosis treatment. ${ }^{75,76}$

Since combined rifampicin-containing formulations have so far not been marketed for the treatment of leprosy, it is likely that the bioavailability of the great majority of rifampicin formulations that have been used for its treatment has been satisfactory. However, if control programmes are considering purchasing large stocks of rifampicin from a new manufacturer in the field, they should first insist on obtaining evidence of its satisfactory bioavailability.

In the studies carried out in Milan by Lepetit, ${ }^{65,69}$ the bioavailability of the rifampicin formulations were compared by giving $600 \mathrm{mg}$ doses of test and control capsules or tablets separated by at least a week to groups of 6-12 healthy volunteers on an empty stomach using a balanced cross-over design. Serum or plasma rifampicin concentrations were determined over a 9- to 12-hour period either by a microbiological plate diffusion assay using Sarcinea lutea or by high pressure liquid chromatography. ${ }^{76}$

In the investigations of the bioavailability of the 2 triple drug formulations referred to above, ${ }^{75}$ rifampicin plasma concentrations were measured by a plate diffusion method using Staphylococcus aureus ${ }^{77}$ and urinary concentrations of rifampicin and deacetylrifampicin were determined colorimetrically af ter extraction into isoamyl alcohol ${ }^{78}$ Some $14-15 \%$ of the rifampicin doses of the standard and combined formulations were recovered in the urine. These findings clearly confirm the evidence obtained over a decade ago by Brechbühler et al. ${ }^{79}$ at Ciba-Geigy in Basle, that colorimetric estimates of the renal elimination of rifampicin plus deacetylrifampicin provide a reliable and much more 
convenient method of assessing rifampicin bioavailability than estimating areas under serum or plasma concentration curves.

The kinetic studies of Brechbühler et al. ${ }^{79}$ also suggest that rifampicin bioavailability studies could be conducted using urine samples collected over just the first 8 hours following dosage, since $78 \%$ of the total urinary excretion occurs during this time. Furthermore, such studies could be carried out with the help of leprosy patients being treated with multidrug therapy and using the laboratory facilities and expertise readily available in many endemic countries. ${ }^{72,73}$

\section{CLOFAZIMINE}

Unlike rifampicin, the pharmacology of clofazimine has been inadequately investigated and is poorly understood. ${ }^{24,47,80,81}$ As a consequence it is difficult to predict the likely impact of using clofazimine formulations of impaired bioavailability on the efficacy of multidrug treatment.

Clofazimine, which is an orange-red dye, can readily be determined in tissues and body fluids by a variety of colorimetric ${ }^{82,83}$ fluorometric, ${ }^{84}$ TLC $^{85}$ and HPLC ${ }^{86}$ methods. Since it is extremely water-insoluble, ${ }^{82}$ ensuring satisfactory absorption of the drug is difficult to achieve. Initial studies of its human pharmacology suggested that it was poorly absorbed; over $90 \%$ of the dose being recovered from the faeces. It was then found that absorption could be improved if it were given in a micronized form, or in olive oil or with fat-rich meals (W A Vischer, personal communication cited in reference 82). According to Yawalkar and Vischer ${ }^{88}$ of Ciba-Geigy, clofazimine absorption varies appreciably from one patient to another and is more complete from micronized material and from oily preparations. When it is given in the form of coarse crystals, only about $20 \%$ of the dose is absorbed, whereas if it is taken orally in the form of a microcrystalline suspension in an oil-wax base (as 'Lamprene'), 'an absorption rate of about $70 \%$ has been achieved' ${ }^{87,88}$ Presumably these estimates were based on faecal elimination studies, but details appear not to have been published. Since clofazimine capsules are made of gelatin, they should be protected from humidity and heat, and are supplied in humidity-resistant containers which should be closed again immediately after use. The capsules may stick together, if improperly stored, but remain usable. They have a shelf-life of 5 years. ${ }^{88}$

There are many remarkable features concerning clofazimine's pharmacology, including its extremely slow elimination and marked tissue accumulation which results in the characteristic skin pigmentation of multibacillary patients undergoing treatment with the drug. Schaad-Lanyi et al. ${ }^{89}$ gave either single $200 \mathrm{mg}$ doses or 8 consecutive $50 \mathrm{mg}$ daily doses of the drug to 12 volunteers and measured plasma clofazimine concentrations over periods of 8-18 days. After giving single doses, the peak plasma clofazimine concentrations were achieved between 8 and 12 hours. They then declined biexponentially, suggesting a distribution of clofazimine from the central compartment to a peripheral compartment, followed by a slow re-equilibration to the central compartment from where it was eliminated. The terminal half-life of the clofazimine after giving a single or 8 consecutive daily doses of the drug was about 10 days.

Less than $1 \%$ of the dose of clofazimine is eliminated in the urine as unchanged drug together with the 3 metabolites that have so far been identified. ${ }^{83,90-92}$ Unless significant 
amounts of other as yet unidentified metabolites of the drug are formed, it is therefore possible that the effective terminal elimination half-life of clofazimine could be considerably longer than 10 days. Levy ${ }^{90}$ has suggested a value of at least 70 days.

The steady accumulation of the drug when ingested on a daily basis is therefore readily understandable and long-term treatment of both patients and experimental animals leads to crystals of the drug being deposited in the tissues. ${ }^{82,83,93-95}$

Because crystalline clofazimine clearly cannot exert an immediate antileprosy effect and because of its uneven tissue distribution, it is impossible to determine clofazimine's minimal inhibitory against $M$. leprae using the mouse foot-pad system. The only controlled clinical trial to compare the efficacy of different regimens of clofazimine (when given as monotherapy) was primarily concerned with the effects of intermittency on antileprosy activity. ${ }^{96}$ Patients were treated for 24 weeks with 5 alternative clofazimine regimens; $200 \mathrm{mg}$ daily 6 days a week, or a total of $1200 \mathrm{mg}$ a month given either 3 times a week, weekly, fortnightly or on 2 consecutive days every month. The daily regimen resulted in more rapid killing of $M$. le prae than the 4 intermittent regimens, showing that increasing the average daily dose from about 43 to $170 \mathrm{mg}$ resulted in a significantly enhanced therapeutic effect. Among the 4 intermittent regimens, therapeutic efficacy decreased as spacing between the doses was increased, despite the fact that all 4 intermittent regimens appeared to give similar skin pigmentation. It was therefore suggested that the accumulated drug did not appear available to exert an antimicrobial effect.

Since the mean daily dosage of clofazimine in the WHO-recommended multidrug treatment is about $59 \mathrm{mg}$, it is likely that if formulations of impaired bioavailability were used, they would be less efficacious. The risk of encouraging eventual relapses through the selection of rifampicin-resistant $M$. le prae ${ }^{22}$ would, however, only be serious if patients were already infected with strains with a high level of dapsone resistance. ${ }^{19}$

The issue of whether or not the absorption of clofazimine is dose-dependent has still not been conclusively settled. With such a water-insoluble drug it might be anticipated that smaller proportions of larger doses would be absorbed and that correspondingly greater proportions of the dose would be eliminated unchanged in the faeces. Banerjee $e t$ $a^{83}$ measured the clofazimine serum concentrations of 17 .patients on long-term treatment with the drug and found mean levels of $0.5 \mu \mathrm{g} / \mathrm{ml}$ among those on treatment 3 times a week with $100 \mathrm{mg}$ clofazimine, and values of $0.7,1.0$ and $1.4 \mu \mathrm{g} / \mathrm{ml}$ when daily doses of 100,300 or $400 \mathrm{mg}$, respectively, were given. Thus serum clofazimine concentrations did not increase in proportion to the mean daily dose. By contrast, Lanyi and Dubois ${ }^{85}$ found peak clofazimine plasma concentrations of $0.07 \mu \mathrm{g} / \mathrm{ml}$ and $0.16 \mu \mathrm{g} / \mathrm{ml}$ after giving single doses of 200 and $400 \mathrm{mg}$ clofazimine, respectively, to a healthy volunteer.

There have been 2 small-scale investigations of the potential dose-dependence of the faecal excretion of clofazimine. Levy ${ }^{90}$ gave single doses of 100,300 and $600 \mathrm{mg}$ clofazimine to 2 volunteers. The percentages of the doses recovered in 3-day faecal collections were 11,8 and 12 from the first, and 61,41 and 74 , respectively, from the second volunteer. Thus while clofazimine absorption did not appear to be dose dependent, it clearly differed very significantly in the 2 subjects. By contrast, Mathur et $a l .{ }^{97}$ found that such increases in individual clofazimine dose-size resulted in average 3-day faecal drug recoveries increasing from 38 to $57 \%$. In the single healthy volunteer studied by Banerjee et al. ${ }^{83} 50 \%$ of a $300 \mathrm{mg}$ dose of the drug was recovered unchanged in 
the faeces over a period of 11 days. In these 2 last studies, clofazimine doses were given on an empty stomach.

The subsequent plasma level study of Schaad-Lanyi et al. ${ }^{89}$ from Ciba-Geigy showed that the absorption of clofazimine can be significantly enhanced if capsules are ingested with food, but provided no evidence concerning the proportion of the dose that is absorbed when the drug is taken in this way. Under field conditions it would be impracticable to try to give monthly supervised clofazimine doses with food, and in any case this would be counterproductive since it would interfere with the absorption of the key supervised rif ampicin dose. ${ }^{60-62}$ Nevertheless, it should be recommended that patients take their daily self-administered clofazimine doses with food.

The bioavailability of clofazimine is clearly problematic. The single-dose plasma concentration protocol used by Schaad-Lanyi et al. ${ }^{89}$ to demonstrate the impaired absorption of clofazimine when taken on an empty stomach could obviously be used for cross-over studies to compare the bioavailabilities of different clofazimine formulations. However, studies with much larger numbers of subjects would first be required to assess how sensitive such an approach would be to detecting differences in relative bioavailability. Because of the minute elimination of clofazimine and its metabolites in the urine, the only other approach to estimating clofazimine bioavailability is on the basis of faecal elimination.

Large scale cross-over studies involving the analysis of complete faecal collections would be a formidable undertaking. An alternative approach would be to give $50 \mathrm{mg}$ daily doses of clofazimine together with other capsules containing a non-absorbable faecal marker such as chromium sesquioxide, ${ }^{98,99}$ and determine the ratios of unchanged clofazimine to chromium in samples from consecutive faecal collections until they reached an equilibrium value. Whichever approach was used to compare the bioavailability of different clofazimine formulations, it would be important to control concomitant dietary intakes as closely as possible.

\section{Conclusion}

The treatment of leprosy with the WHO-recommended multidrug therapy would be seriously threatened if rifampicin formulations of impaired bioavailability were used. Fortunately such formulations can readily be identified using relatively simple methods. The consequences of treating patients with substandard clofazimine formulations are less certain and the difficulties of assessing their relative bioavailability formidable. Problems of dapsone bioavailability have never been encountered and if they did occur they would be unlikely to be of significant importance.

National Institute for Medical Research

G A Ellard

London NW7 1 AA

\section{References}

1 McDougall AC, Georgiev GD. Priorities in leprosy control. Lepr Rev, 1989; 60: 1-7.

2 WHO A Guide to Leprosy Control. Second Edition. WHO: Geneva, 1988.

$3 \mathrm{Ji}$ B, Grosset JH. Recent advances in the chemotherapy of leprosy. Lepr Rev, 1990; 61: 313-29. 
4 Noordeen SK. A look at world leprosy. Clayton Memorial Lecture. London, 1.10.90. Lepr Rev, 1991; 62: 72-86.

5 Noordeen SK. Leprosy control through multidrug therapy (MDT). Bull WHO, 1991; 69: 263-9.

6 WHO Model Prescribing Information. Drugs used in mycobacterial diseases. WHO: Geneva, 1991.

7 Noordeen SK. Elimination of leprosy as a public health problem. Lepr Rev, 1992; 63: 1-4.

8 WHO Expert Committee on Leprosy. Sixth Report. Technical Report Series No. 768. WHO: Geneva, 1988.

9 Noordeen SK, Lopez Bravo L, Sundaresan TK. Estimated number of leprosy cases in the world. Bull WHO, 1992; 70: 7-10.

10 Styblo K, Meijer J. Impact of BCG vaccination programmes in children and young adults on the tuberculosis problem. Tubercle, 1976; 57: 17-43.

11 Sutherland I. The epidemiology of tuberculosis-is prevention better than cure? Bull Int Union Tuberc, 1981; 56: $127-34$.

12 Sutherland I. Research on the control of tuberculosis and leprosy in the community. Brit Med Bull, 1988; 44: 665-78.

13 Kochi A. The global tuberculosis situation and the new control strategy of the World Health Organization. Tubercle, 1991; 72: 1-6.

14 Shepard CC, Levy L, Fasal P. Rapid bactericidal effect of rif ampin on Mycobacterium leprae. Am J Trop Med Hyg, 1972; 21: 446-9.

15 Shepard CC, Levy L, Fasal P. Further experience with the rapid bactericidal effect of rifampin on Mycobacterium leprae. Am J Trop Med Hyg, 1974; 23: 1120-4.

16 Feldman RA, Sturdivant M. Leprosy in the United States, 1950-69; An epidemiological review. Southern Med J, 1976; 69: 970-8.

17 Dominguez VM, Garbajosa PG, Gyi MM, Tamondong CT, Sundaresan T, Bechelli LM, Lwin K, Sansarricq H, Walter J, Noussitou, FM. Epidemiological information on leprosy in the Singu area of Upper Burma. Bull WHO, 1980; 58: 81-9.

18 Ponnighaus JM, Fine PEM, Maine N, Bliss L, Kalambo M, Ponnighaus I. The Lepra Evaluation Project (LEP), an epidemiological study of leprosy in northern Malawi. II: Prevalence rates. Le pr Rev, 1988; 59: 97-112.

19 Ellard GA. Rationale of the multidrug regimens recommended by a World Health Organization study group of chemotherapy of leprosy for control programs. Int J Lepr, 1984; 52: 395-401.

$20 \mathrm{Ji}$ B. Drug resistance in leprosy—a review. Lepr Rev, 1985; 56: 265-78.

21 Levy L. The Kellersberger Memorial Lecture 1984. Chemotherapy of leprosy-a tool for leprosy control. Ethiop Med J, 1985; 23: 31-42.

22 Grosset JH, Guelpa Lauras CC, Bobin P, Brucker G, Cartel JL, Constant-Despotes M, Flageul B, Frederic M, Guillaume JC, Millan J. Study of 39 documented relapses of multibacillary leprosy after treatment with rifampin. Int J Lepr, 1989; 57: 607-14.

23 Ellard GA. The chemotherapy of leprosy. Int J Lepr, 1990 and 1991; 58: 704-16 and 59: 82-94.

24 WHO Study Group. Chemotherapy of leprosy for control programmes. Technical Report Series, No. 675. WHO: Geneva, 1982.

${ }^{25}$ Hong Kong Tuberculosis Treatment Services and East African and British Medical Research Councils. First-line chemotherapy in the retreatment of bacteriological relapses of pulmonary tuberculosis following a short-course regimen. Lancet, 1976; i: 162-3.

${ }^{26}$ Helmy HS, Pearson JMH, Waters MFR. Treatment of moderately severe erythema nodosum leprosum with clof azimine-a controlled trial. Le pr Rev, 1972; 42: 167-77.

27 UNDP/World Bank/WHO Special Programme for Research and Training in Tropical Disease: Tropical diseases. Progress in international research, 1987-88. Ninth programme report, pp. 97-9. 1989 World Health Organization, Geneva.

28 Panniker VK cited in Constant-Desportes M, Guelpa-Lauras CC, Carolina JC, Leoture A, Grosset JH, Sansarricq H. A case of relapse with drug-susceptible M. leprae af ter multidrug therapy. Int J Lepr, 1991; 59: $242-7$.

29 THELEP: Subcommittee on Clinical Trials of the Chemotherapy of Leprosy Scientific Working Group of the UNDP/World Bank/WHO Special Programme for Research and Training in Tropical Diseases. Persisting Mycobacterium leprae among THELEP trial patients in Bamako and Chingleput. Lepr Rev, 1987; 58: 325-37.

30 Boerrigter G, Ponnighaus JM, Fine PEM, Wilson RJ. Four-year follow-up results of a WHO-recommended multi-drug regimen in paucibacillary leprosy patients in Malawi. Int J Lepr, 1992; 59: 255-61.

31 Georgiev GD, McDougall AC. Skin smears and the bacterial index (BI) in multiple drug therapy leprosy control programs: An unsatisfactory and potentially hazardous state of affairs. Int J Le pr, 1988; 56: 101-4.

32 Becx-Bleumink M. Allocation of patients to paucibacillary or multibacillary drug regimens for the treatment of leprosy-A comparison of methods based mainly on skin smears as opposed to clinical methodsalternative clinical methods for classification of patients. Int J Lepr, 1991; 59: 292-303.

33 Becx-Bleumink M. Experience with WHO-recommended multidrug therapy (MDT) for multibacillary (MB) leprosy patients in the leprosy control programme of the All Africa Leprosy and Rehabilitation Training 
Centre in Ethiopia: Appraisal of the recommended duration of MDT for M B patients. Int J Lepr, 1991; 59: 558-68.

34 Li HY, Yu XL, Zhang MS, Duan CX, Huang WB, Zhang SB, Zhu K, Ma JF. Short-term multidrug therapy in multibacillary leprosy. Review of 80 cases in two provinces of China (1983-88). Int J Lepr, 1989; 57: 622-7.

35 Noordeen SK. Personal communication, 1992.

36 Winsley BE, McDougall AC, Brown KE. Chemotherapy of leprosy; 'bubble' or 'calendar' packs for the administration of rifampin, dapsone, clofazimine, or prothionamide/ethionamide. Int J Lepr, 1983; 51: $592-4$.

37 Georgiev GD, Kielstrup RW. Blister calendar packs for the implementation of multidrug therapy in DANIDA-assisted leprosy control projects in India. Lepr Rev, 1987; 58: 249-55.

38 Georgiev GD, McDougall AC. Blister calendar packs-potential for improvement in the supply and utilization of multiple drug therapy in leprosy control programs. Int J Lepr, 1988; 56: 603-10.

39 McDougall AC. Implementing multiple drug therapy for leprosy. Oxfam, 1988.

40 Grosset JH, Ji B, Guelpa-Lauras CC, Perani EG, N'Deli LN. Clinical trial of pefloxacin and ofloxacin in the treatment of lepromatous leprosy. Int J Lepr, 1990; 58: 281-95.

${ }^{41}$ Lode H, Höffken N, Olschewski P, Sievers B, Kirch A, Borner K, Koeppe P. Pharmacokinetics of ofloxacin after parenteral and oral administration. Antimicrob Agents Chemother, 1987; 31: 1338-42.

42 Yuk, JH, Nightingale CH, Quintiliani R, Sweeney KR. Bioavailability and pharmacokinetics of ofloxacin in healthy volunteers. Antimicrob Agents Chemother, 1991; 35: 384-6.

43 Waters, MFR. Personal communication, 1992.

44 WHO Press release 3/2/1992.

45 British Pharmacopoeia. Her Majesty's Stationery Office, London, 1988.

46 Martindale. The Extra Pharmacopoieia. 29th Edition (ed. Reynolds JEF). The Pharmaceutical Press, London, 1989.

47 Therapeutic Drugs (ed. Dollery, CT). Churchill Livingstone; Edinburgh, London, Melbourne, New York, Tokyo and Madrid, 1991.

48 Orzech CE, Nash NG, Daley RD. Dapsone. In Analytical profiles of drug substances, Vol. 5, pp. 88-114. K Florey (ed.). Academic Press, New York, 1976.

49 Gallo GG, Radaelli P. Rifampin. In Analytical profiles of drug substances, Vol. 5, pp. 467-513. K Florey (ed.). Academic Press, New York, 1976.

50 Pieters FAJM, Zuidema J. The absolute oral bioavailability of dapsone in dogs and humans. Int $J$ Clin Pharmacol Therap Toxicol, 1987; 25: 396-400.

51 Peters JH, Gordon GR, Murray JF, Fieldsteel AH, Levy L. Minimal inhibitory concentration of dapsone for Mycobacterium leprae in rats. Antimicrob Agents Chemother, 1975; 8: 551-7.

52 Levy L, Peters JH. Susceptibility of Mycobacterium leprae to dapsone as a determinant of patient response to acedapsone. Antimicrob Agents Chemother, 1976; 9: 102-12.

53 Zuidema J, Hilbers-Modderman ESM, Merkus FWHM. Clinical pharmacokinetics of dapsone. Clin Pharmacokin, 1986; 11: 299-315.

${ }^{54}$ Ellard GA. Assaying dapsone in mouse diets. Lepr Rev, 1980; 51: 321-3.

55 Ahmad RA, Rogers HJ. Plasma and salivary pharmacokinetics of dapsone estimated by a thin-layer chromatographic method. Eur J Clin Pharmacol, 1980; 17: 129-33.

56 Peters JH, Gordon GR, Colwell WT. The fluorimetric measurement of 4,4'-diaminodiphenyl sulfone and its acetylated derivates in plasma and urine. J Lab Clin Med, 1970; 76: 338-48.

57 Jenner PJ. The determination of antimycobacterial drugs in body fluids by high-performance liquid chromatography. In Progress in Medical Microbiology. Reeves D, Ullman U. (eds). Stuttgart: Fischer, 1986, Vol. 2. pp. 153-64.

58 Gordon GR, Ghoul DC, Peters JH. Identification and quantitation of impurities in dapsone preparations. $J$ Pharmaceut Sci, 1975; 64: 1205-7.

59 Levy L, Shepard CC, Fasal P. The bactericidal effect of rifampicin on M. leprae in man: (a) Single doses of 600, 900 and $1200 \mathrm{mg}$; and (b) Daily doses of $300 \mathrm{mg}$. Int J Lepr, 1976; 44: 183-7.

${ }^{60}$ Kenny MT, Strates B. Metabolism and pharmacokinetics of the antibiotic rifampin. Drug Metab Rev, 1981; 12: $159-218$.

61 Keberle H. Physico-chemical factors of drugs affecting absorption, distribution and excretion. Acta Pharmacol Toxicol, 1971; 29 Suppl 3: 30-47.

62 Siegler DI, Bryant M, Burley DM, Citron KM, Standen SM. Effect of meals on rifampicin absorption. Lancet, 1974; ii: 197-8.

63 Maggi N, Furesz S, Pallanza R, Pelizza G. Rifampicin desacetylation in the human organism. ArzneimittelForsch, 1969; 19: 651-4.

64 Holdiness MR. Chromatographic analysis of antituberculosis drugs in biological samples. J Chromatogr, 1985; 340: 321-59.

65 Buniva G, Pagani V, Carozzi A. Bioavailability of rifampicin capsules. Int J Clin Pharmacol Therap Toxicol, 1983; 21: 404-9. 
66 Boman G, Lundgren P, Stjernström G. Mechanism of the inhibitory effect of PAS granules on the absorption of rifampicin; Adsorption of rifampicin by an excipient, bentonite. Eur J Clin Pharmacol, 1975; 8: 293-9.

${ }^{67}$ Cavenaghi R. Rifampicin raw material characteristics and their effect on bioavailability. Bull Int Union Tuberc Lung Dis, 1989; 64: 36-7.

${ }^{68}$ Aspesi F. Dissolution testing. Bull Int Union Tuberc Lung Dis, 1989; 64: 37-8.

69 Acocella G. Human bioavailability studies. Bull Int Union Tuberc Lung Dis, 1989; 64: 38-40.

70 Anonymous. Editorial. Multi-drug formulations. Indian J Tuberc, 1988; 35: 161-2.

71 Girling DJ. Discussion. Satellite Symposium on quality control of antituberculosis drugs. Bull Int Union Tuberculosis Lung Dis, 1989; 64: 40-1.

72 Fox W. Drug combinations and the bioavailability of rif ampicin. Tubercle, 1990; 71: 241-5.

${ }^{73}$ Fox W. Tuberculosis in India-past, present and future. Indian J Tuberc, 1990; 37: 175-213.

74 Long MW, Snider DE, Farer LS. U.S. Public Health Service Cooperative Trial of three rif ampicin-isoniazid regimens in the treatment of pulmonary tuberculosis. Am Rev Resp Dis, 1979; 119: 879-94.

75 Ellard GA, Ellard DR, Allen BW, Girling DJ, Nunn AJ, Teo SK, Tan TH, Ng HK, Chan SL. The bioavailability of isoniazid, rifampin, and pyrazinamide in two commercially available combined formulations designed for use in the short-course treatment of tuberculosis. Am Rev Respir Dis, 1986; 133: 1076-80.

76 Acocella G, Nonis A, Gialdroni-Grassi G, Grassi C. Comparative bioavailability of isoniazid, rif ampin and pyrazinamide administered in free combination and in a fixed triple formulation designed for daily use in antituberculosis chemotherapy. Amer Rev Respir Dis, 1988; 138: 882-85.

77 Dickinson JM, Aber VR, Allen BW, Ellard GA, Mitchison DA. Assay of rif ampicin in serum. J Clin Pathol, 1974; 27: 457-62.

78 Sunahara S, Nakagawa H. Metabolic study and controlled clinical trials of rifampicin. Chest, 1972; 61: 526-32.

79 Brechbühler S, Fluehler H, Riess W, Theobald W. The renal elimination of rif ampicin as a function of the oral dose. A convenient way to assess relative bioavailability. Arzneimittel-Forsch/Drug Res, 1978; 28: 480-3.

80 Holdiness MR. Clinical pharmacokinetics of clofazimine. Clin Pharmacokin, 1989; 16: 74-85.

81 Venkatesan K. Clinical pharmacokinetic considerations in the treatment of patients with leprosy. Clin Pharmacokinet, 1989; 16: 365-86.

82 Barry VC, Buggle K, Byrne J, Conalty ML, Winder F. Absorption, distribution and retention of the riminophenazine compounds in the experimental animal. Irish J Med Sci, 1960; 416: 345-52.

83 Baner jee DK, Ellard GA, Gammon PT, Waters MFR. Some observations on the pharmacology of clofazimine (B663). Amer J Trop Med Hyg, 1974; 23: 1110-15.

${ }^{84}$ Dill WA, Chucot L, Glazko AJ. A new analytical procedure for B663 (clofazimine). Int J Lepr, 1970; 38: $355-6$.

${ }^{85}$ Lanyi Z, Dubois JP. Determination of clofazimine in human plasma by thin-layer chromatography. $J$ Chromatogr, 1982; 232: 219-23.

86 Peters JH, Hamme KJ, Gordon GR. Determination of clofazimine in plasma by high-performance liquid chromatography. J Chromatogr, 1982; 229: 503-8.

87 Vischer WA. The experimental properties of G 30320 (B 663)--a new anti-leprotic agent. Lepr Rev, 1969; 40: 107-10.

88 Yawalka SJ, Vischer W. Lamprene (clofazimine) in leprosy. Lepr Rev, 1979; 50: 135-44.

89 Schaad-Lanyi Z, Dieterle W, Dubois JP, Theobald W, Vischer W. Pharmacokinetics of clofazimine in healthy volunteers. Int $J$ Lepr, 1987; 55: 9-15.

90 Levy L. Pharmacologic studies of clofazimine. Am J Trop Med Hyg, 1974; 23: 1097-109.

91 Feng PCC, Fenselau CC, Jacobson RR. Metabolism of clofazimine in leprosy patients. Drug Metabolism Disposition, 1981; 9: 521-4.

92 Feng PCC, Fenselau CC, Jacobson RR. A new urinary metabolite of clofazimine in leprosy patients. Drug Metabolism Disposition 1982; 19: 286-8.

93 McDougall AC. Electron microscope studies of the antileprosy drug B 663 (Clofazimine, Lamprene). Int $J$ Lepr, 1974; 42: 1-12.

94 Mansfield RE. Tissue concentrations of clofazimine (B 663) in man. Am J Trop Med Hyg, 1974; 23: 1116-19.

95 Desikan KV, Balakrishnan S. Tissue levels of clofazimine in a case of leprosy. Lepr Rev, 1976; 47: $107-13$.

96 Collaborative effort of the U.S. Leprosy Panel and the Leonard Wood Memorial. Spaced clofazimine therapy of lepromatous leprosy. Am J Trop Med Hyg, 1976; 25: 437-44.

97 Mathur A, Vankatesan K, Bharadwaj VP, Ramu G. Evaluation of effectiveness of clofazimine therapy. 1. Monitoring of absorption of clofazimine from gastrointestinal tract. Ind $\boldsymbol{J}$ Le pr, 1985; 57: 146-8.

98 Rose GA. Experiences with the use of interrupted carmine red and continuous chromium sequioxide marking of human faeces with reference to calcium, phosphorus and magnesium. Gut, 1964; 5: 274-9.

99 Roberts NB, Fairclough D, Taylor WH. Plasma emission spectrometry: measurement of calcium, phosphorus and chromium in metabolic balance studies. Ann Clin Biochem, 1984; 21: 213-17. 